\title{
The Application and the Prospect of Remanufacturing Technologies in the Metallurgical Industry
}

\begin{abstract}
Metallurgical equipment is subjected to severe working conditions and the components suffer from various types of physical damages such as abrasion, corrosion and crack. Advanced surface engineering technologies and resistant coatings on the damaged surface can improve surface properties, extend service lives, reduce maintenance costs and improve product quality in the metallurgical industry. This paper introduces remanufacturing technologies, including electroplating, overlaying welding, thermal spraying and laser surface cladding and their applications in the metallurgical industry, and analyzes the development tendency and prospect of remanufacturing technologies.
\end{abstract}

Keywords: remanufacturing technology, electroplating, overlaying welding, thermal spraying, laser surface cladding

\section{Introduction}

Remanufacturing uses the damaged components as the core and uses advanced surface engineering technologies as a repair method. The resistant coatings are prepared on the damaged surface in order to reduce physical damages such as abrasion, corrosion and crack. In the whole process of remanufacturing, the demand for energy and resources and the emission of waste solid and waste gas are very few. Therefore, remanufacturing shows the feature of green manufacturing $(\mathrm{Xu}, 2010)$.

In the metallurgical industry, a large amount of machinery equipment is subjected to severe conditions such as high temperature, high speed, high load and corrosion, which lead to various types of service-induced damages to the components, such as abrasion and corrosion are unavoidable. The service-induced damages will affect

Manuscript received February 10, 2016; accepted May 17, 2016

Jie Xiong ( $ه$ ), Jian-cheng Fan, Jv Yuan

Equipment Department of Baoshan Iron \& Steel Co. Ltd., Shanghai, 201900, China

Email: jiexiong@baosteel.com the normal operation of equipment and sometimes reduce the product quality. As China's economy has entered a new stage, the competition of steel industry is growing fiercer. To achieve victory in the fierce competition, steel enterprises need to improve the product quality and reduce the product cost. Typical remanufacturing technologies, such as electroplating, overlaying welding, thermal spraying and laser surface cladding can improve the surface properties, enhance the quality, extend the service lives and reduce maintenance costs of the components. Thus, remanufacturing technologies have been widely used in the metallurgical industry.

To meet the needs of the metallurgical industry, thermal spraying is used to improve the abrasion resistance and extend the service lives of the continuous casting mold, process roller of cold rolling mill and strip treatment line (thereafter process roller) and fan impeller. Overlaying welding is used to resolve the technical issues such as size restoration and increase abrasion resistance of sintering breaker, continuous casting roller and transport roller in heavy plate mill. Laser surface cladding is used to resolve the technical issues such as on-site repair and anticorrosion of rolling mill housing. The traditional repair methods for key components, such as fan impeller, flat casing of spindle in main drive train of rolling mill and flying shear crankshaft, have been improved and process risks have been reduced.

\section{Extended application of electroplating and overlay welding}

\subsection{New application field of electroplating}

As a traditional surface engineering technology, electroplating has been extensively used in the metallurgical industry, such as the repair and remanufacturing of the components. There are two examples. One is that surface chrome plating is used to increase the abrasion resistance and extend the service life of the process roller. Another is 
Table 1

The Comparison of Service Lives between the Rollers with and without Chrome Plating

\begin{tabular}{lcc}
\hline Machine set & Equipment name & $\begin{array}{c}\text { Service lives } \\
\text { (without chrome plating) }\end{array}$ \\
\hline Pickling line & Pinch roller & 3 months \\
(with chrome plating) & 6 months & 3 months \\
Cold rolling mill & Turning roller & 2 months \\
Tinning line & Turning roller & $3-6$ months \\
& Tension roller & 20 months \\
Hot-dipped galvanizing line & Furnace roller & 6 months \\
\hline
\end{tabular}

that new Co-Ni plating is applied to the copper plate of mold and greatly improves the cooling effect and average value of passing steel.

The service lives of various types of the process roller have been extended significantly by using surface chrome plating. These rollers include pinch roller and turning roller in pickling line, turning roller in cold rolling mill, tension roller and furnace roller in tinning line, and turning roller in hot-dipped galvanizing line. The comparison of service lives between the rollers without and with chrome plating is listed in Table 1.

The development of the continuous casting mold surface treatment processes begins from the original chrome plating to $\mathrm{Ni}$ plating, Ni-Fe plating and $\mathrm{Ni}-\mathrm{Co}$ plating. Although these traditional processes have been widely used, they have some disadvantages in practice. The surface properties of various kinds of plating show significant differences. The comparison of average value of passing steel among these plating is shown in Figure 1. To meet the needs of long service life of plating and matching the service lives of the wide copper plate and the narrow copper plate in mold, a new Co-Ni plating (Not NiCo plating) including the application of thermal spraying

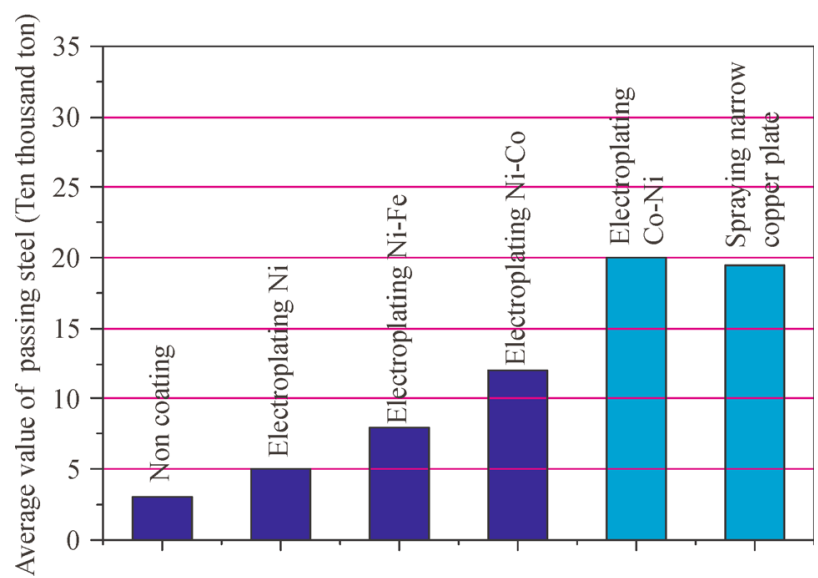

Figure 1. Service life and surface treatment of continue casting mold. (Hou, Ren, Gao, \& Wang, 2012) and metalizing technology has been developed and average value of passing steel can be improved over three times on the narrow copper plate, compared with ordinary $\mathrm{Ni}$ plating.

2.2 New application of overlay welding material and process

Overlay welding is a traditional technology for repairing machinery components. It is used to repair wear-out components and produce double-metal part and metal layers with abrasion, corrosion resistance or special properties on the surface and edges. It has the advantages of saving materials, reducing manufacturing costs and extending service lives.

The roller table in hot rolling mill, such as transporting and pinching roller in scale box, is easy to get corrosive wear due to high temperature and high humidity. The service life of the roller cannot meet the need of production because it is shortened by corrosive wear. The wear-out roller were repaired by using overlay welding with ordinary materials previously but the service life of the repaired roller cannot meet the demands. On the other hand, by using innovative overlay-welding material, the corrosion resistance of roller surface has been improved significantly and its service life has been extended more than one time.

As a new manufacturing and repair technology, plasma transferred arc (PTA) welding has been applied in the metallurgical industry. It has been used to manufacture the spiral conveyor blade with high content of ceramic and the coating of turning plate of DRI stock distributor (as shown in Figure 2). Compared with the overhaul period of the imported blade and turning plate, that of the domestic product has been extended three times. In the overhaul, the domestic products still remain in good surface condition and can be serviceable again. In addition, PTA welding has been used in zinc pot assembly of hot-dipped galvalume line. The spray-welding components, such as the shaft sleeve, lining and scraper of the sink roller and stabilizing roller, have passed the operating tests and their service lives have reached or exceeded those of new components. 

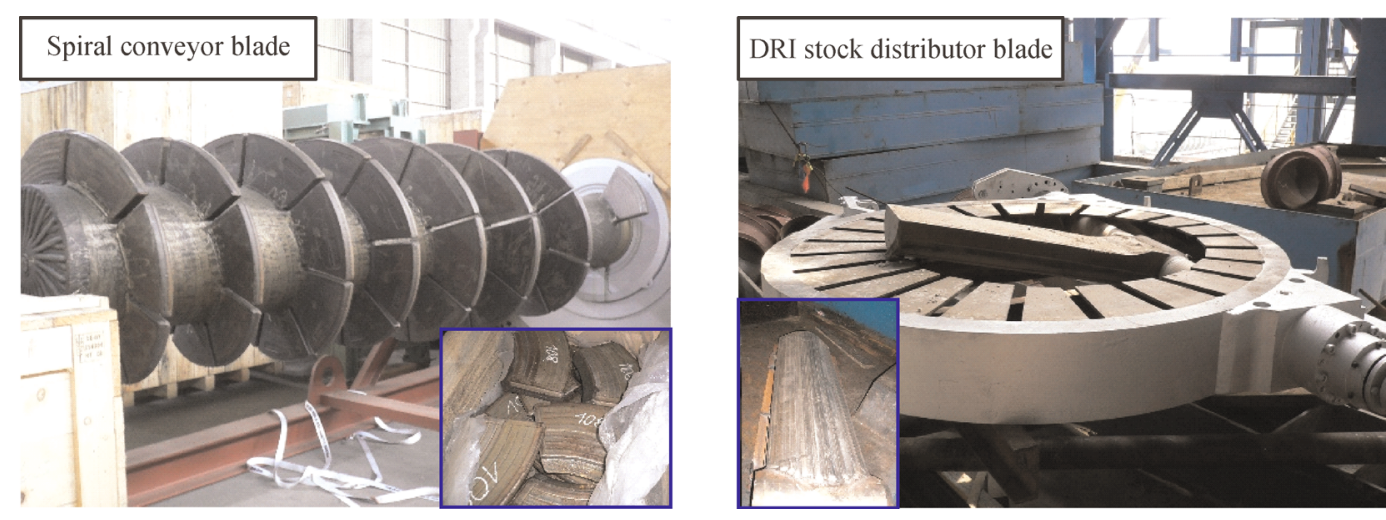

Figure 2. The spiral conveyor blade and the turning plate coating of DRI stock distributor blade.

\section{Extensive application of thermal spraying}

Thermal spraying is a set of coating processes for metal and nonmetal coating application. The thermal spraying materials (in powder, wire, or rod form) are heated to a molten or semi-molten state and the heated particles are accelerated and propelled toward a prepared surface by either process gases or atomization jets. Then, the particles deposit on the surface and form a lamellar structure $(\mathrm{Hu}$, 1994). At present, thermal spraying processes, including high-velocity oxy fuel spray (HVOF), plasma spray and detonation gun spray, have been applied to improve the physical and chemical properties of the component surface, such as fan impeller, cold roller, furnace roller and gas turbine impeller, in order to resist abrasion, corrosion and nodulation. Compared with electroplating and overlay welding, thermal spraying is more environmentally friendly and efficient.

\subsection{Application in cold roller}

A typical application of thermal spraying is the sink roller of hot-dipped galvanizing line. No coating has been applied to the roller previously. The service life of the uncoated roller is about one week. However, the service life of the roller has been extended to three weeks through the use of corrosive wear resistant refractory zinc thermal spray coatings. The surface quality of the galvanized plate has also been controlled effectively (Chen, Fan, \& Yuan, 2009).

Other typical applications are related to the measuring tension roller of cold rolling mill, the scale breaking roller of pickling line, the working roller and leveling roller of tension leveller and the tension roller of hot dipped galvanizing line. The original surface treatment process is surface hardening or chrome-plating and their service lives has been extended obviously by thermal spraying as shown in Table 2.

\subsection{Application of thermal spraying with nano-materials}

The accumulated burl on furnace roller surface is frequently occurred under high temperature in uniform heating region of heat treatment line for heavy plate and of continuous annealing line for cold strip. Therefore, the furnace have to stop regular maintenance and remove the accumulated burl on roller surface. This problem about the accumulated burl on high temperature furnace roller surface has been solved thoroughly and the service life of the roller has been extended from 3 months to 18-24 months by using anti-accumulated-burl nano-material and plasma spraying as shown in Figure 3. In addition, the problem on the erosion and corrosion of blast furnace TRT impeller has been solved and the service life of the impeller

Table 2

The Comparison of Service Lives between the Rollers with and without Chrome Coatings

\begin{tabular}{lccc}
\hline Machine set & Equipment name & $\begin{array}{c}\text { Service life } \\
\text { (without chrome plating) }\end{array}$ & $\begin{array}{c}\text { Service life } \\
\text { (with thermal spraying) }\end{array}$ \\
\hline Cold rolling mill & Measuring tension roller & $2-3$ months & $12-18$ months \\
& Scale breaking roller & 1 month & $3-6$ months \\
Pickling line & Working roller of tension leveller & 0.5 month \\
& Leveling roller of tension leveller & 1 month & $3-4$ months \\
Hot-dipped galvanizing line & Tension roller & 12 months & $6-8$ months \\
\hline
\end{tabular}




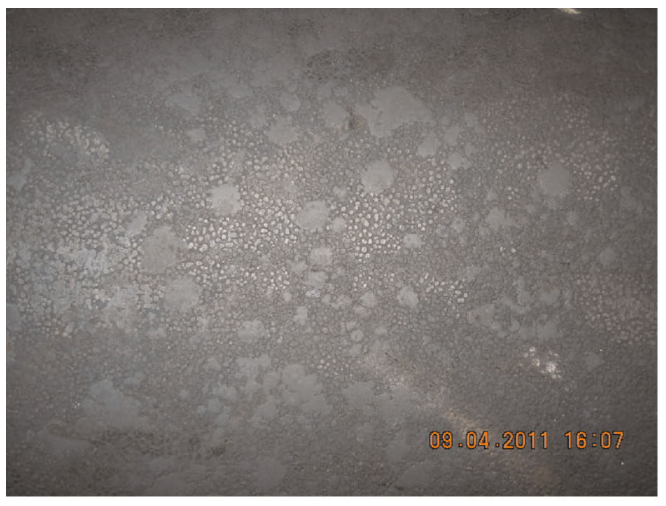

(a) Roller without coating

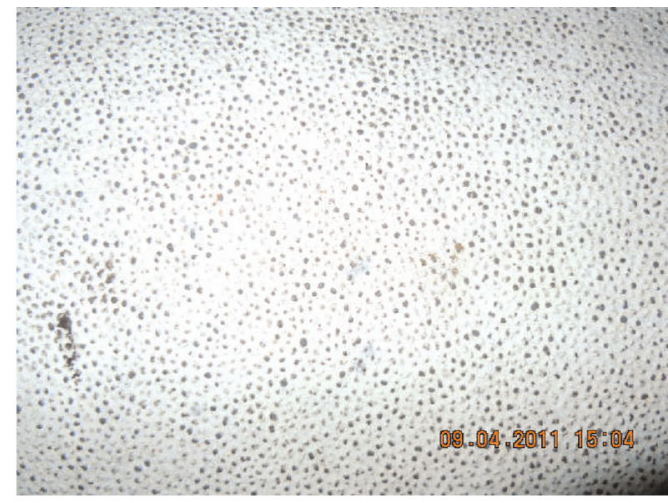

(b) Roller with nano-material coating

Figure 3. The comparison of protecting effect with and without coating on furnace roller in heat treatment line for heavy plate (after service 12 months).
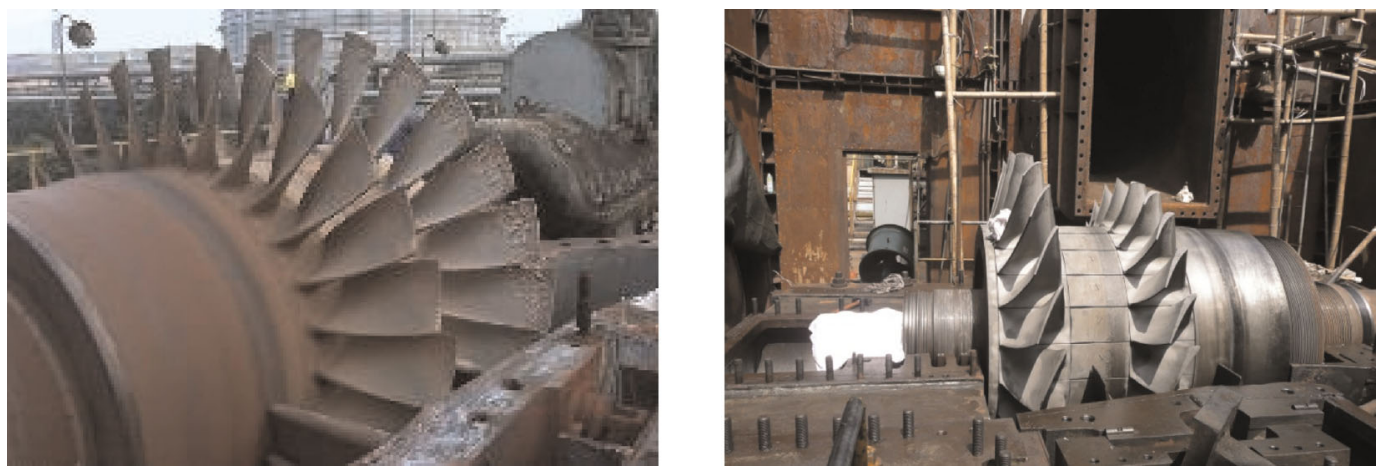

Figure 4. The comparison of protecting effect whether it has the coating on TRT impeller.

has been extended from (3-6) months to (18-24) months by using acid and chloride ion resisting nano-material and plasma spraying as shown in Figure 4.

\section{Applied researches of laser surface clad- ding}

Laser surface cladding is a set of surface engineering processes developed in the 1980s. These processes are divided into three major categories: laser surface strengthening, laser surface modification and laser surface cladding. The main advantages of laser surface cladding are non-contact process and controllable heat input. In addition, its outstanding features are high energy density, dense cladding material, high bonded strength, low diluting rate and little heat affected zone. The abrasion and oxidation resistance of the component surface can be improved greatly by using laser surface cladding.

\subsection{Repairing main drive-train equipment of the rolling mill}

The main drive-train equipment of rolling mill consists of motor, reducer, gear pinion, spindle and coupling. The working condition of spindle is extremely severe. It transmits rolling torque under the condition of different loaded angles, and its structure and size are restricted by working space. The swing diameter, on the roller side, must be smaller than the minimum diameter of the roller. The spare parts of the main drive-train equipment have high costs and long manufacturing period.

A typical application is the universal joint shaft of main drive-train of heavy plate mill, which works under the conditions of high temperature, high humidity and heavy load and the bearing bore of yoke suffers from deformation, corrosive wear and crack in some areas. It is made from quenched and tempered casting steel named GS33CrNiMo744 according to German DIN standard and has high machining precision. Therefore, it cannot be repaired through the traditional methods. However, the crack has been repaired successfully through laser surface cladding and the bearing bores have been restored to the original design precision. The repaired universal joint shaft meets the demand of normal operation.

Another typical application is the flat casing of spindle in main drive-train of heavy plate mill, whose inner hole had been worn down heavily after a year of service. The clearance between the flat casing and the flat head of the roller is far beyond the allowable standard and has a serious impact on the normal operation of the mill. Because the flat 
casing works under the high stress condition, the required mechanical strength cannot be obtained by using ordinary overlay welding. The worn casing has been repaired by using laser surface cladding and the inner holes have been restored to the original design precision. Its abrasion rate is only one sixth to one eighth of the original ones.

\subsection{The on-site repair of the rolling-mill housing}

The hot rolling mill and heavy plate rolling-mill housing are working under severe conditions, such as high temperature, humidity, dust and heavy rolling load. The erosion and corrosion usually occurred on the side-surface and bottom-surface of the rolling-mill housing window after $10-15$ years of service. In addition the clearance between the housing and the bearing seat cannot be controlled effectively and often exceeds the maximum allowable value. Moreover, the clearance will worsen the working conditions of main drive-train equipment, aggravate the vibratory shock and influence the control of the plate shape, ultimately degrade the product quality. The increased clearance of the mill housing may also cause the axial running of the roller and the bearing damage.

The rolling-mill housing is irremovable and the working stress is complicated. The deformation and the potential risk are unavoidable if it is repaired by electronic arc welding with stainless steel (Chen, Fu, \& Yuan, 2009). Based on the decreased shape dimension of laser device and industrial robot, the rolling-mill housing has been repaired on-site by using laser surface cladding, as shown in Figure 5. Up to now, more than ten rolling-mill housings have been repaired on-site. Their window precision has been restored and their service lives have been extended greatly.

4.3 The application of laser cladding on large power equipment

A large amount of power equipment, such as air separation unit, large blower set and gas booster, which provides

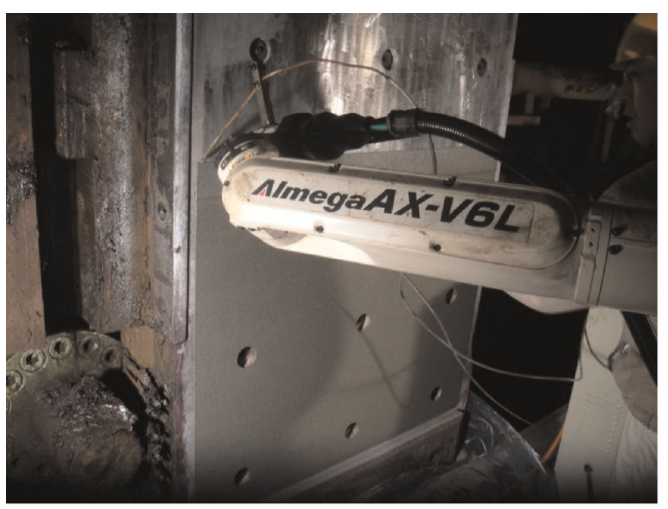

(a) Laser cladding energy for iron-making, steel-making and rolling, is widely used in steel enterprises. These equipment is expensive and works at the speed of thousands of rpm or at even higher speed. Once an accident happens, the outcome would be terrible and serious.

A typical application is on the impeller of large air compressor. The crack of the impeller cannot be solved thoroughly by drilling stop-crack holes at the end of the crack and cannot be repaired by using ordinary welding because of the deformation and the reduced properties in the wide heat-affected region. As shown in Figure 6, the impeller has been repaired successfully by using laser cladding. The repaired impeller works properly and its vibration amplitude is smaller than that of the original ones (Liu \& Fan, 2007).

\section{Prospects}

The developing new remanufacturing technologies, such as laser surface cladding and additive manufacturing, will be widely applied in metallurgy industry. Shaft sleeve of sink roller (for preventing liquid zinc corrosion), gas turbine impeller and composite liner are excellent application examples of laser surface cladding. Thermal spraying has been used to resolve the technical issues of the erosion and corrosion of fan impeller. Plasma spraying with nanomaterials has been used to resolve the accumulated burl on high temperature furnace roller surface and the acid and chloride-ion resistance of TRT impeller. The development trend in metallurgy components remanufacturing is the integration of multiple technologies and applications. For example, the different-scale components can be remanufactured by using overlay welding to repair damages with large size in substrate, using laser cladding to deposit the surface or sub-surface function layers, and using thermal spraying to produce the needed surface properties. Based on the economic availability, more than one half of the components can be remanufactured in the metallurgy industry and remanufacturing has become an important

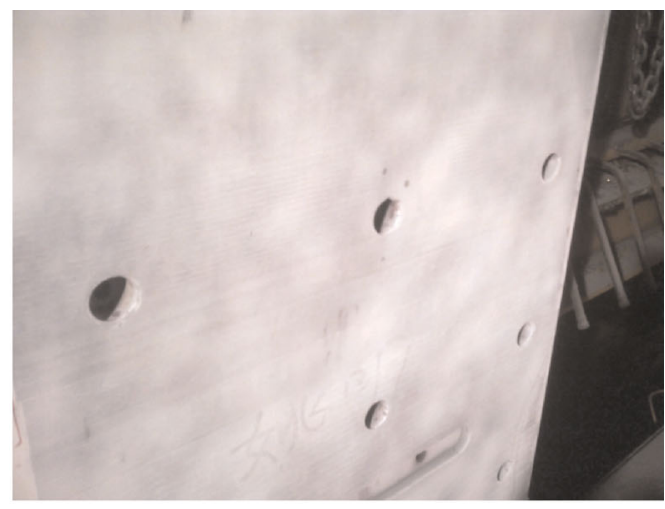

(b) After laser cladding (Polished and NDT)

Figure 5. On-site laser cladding repair of rolling-mill housing. 


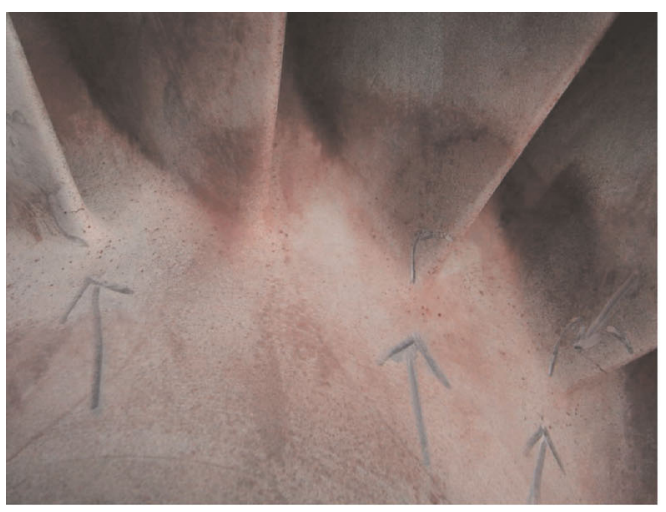

(a) Before repairing

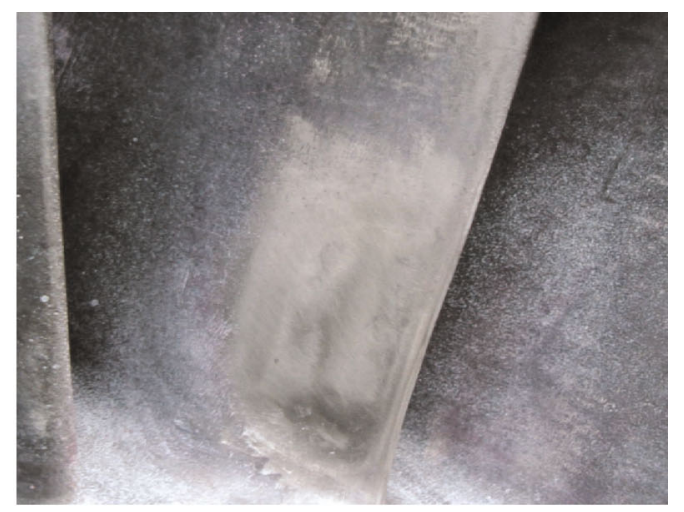

(b) After repairing

Figure 6. Laser cladding repair of large air compressor impeller.

technological approach to reduce the cost for steel enterprises.

\section{References}

Chen, X., Fan, J., \& Yuan, J. (2009). Application and prospect of surface technology in Baoshan iron and steel plant. Metallurgical Equipment, Special Issue, 92-93.

Chen, X., Fu, W., \& Yuan, J. (2009). Research on laser cladding of mill housing. Surface Engineering, 38, 87-89.

Hou, F., Ren, Q., Gao, J., \& Wang, Q. (2012). Research and application of remanufacturing technology in continuous casting core equipments. 7th China International Steel Congress.

Hu, C. (1994). Thermal spraying principles and application. Science and Technology of China Press, 3.

Liu, Z., \& Fan, J. (2007). Analysis and repair measures of crack of centrifugal compressor. Compressor Blower \& Fan Technology, 5, 34-39.

Xu, B. (2010). The situation and frontier of remanufacturing. Transactions of Materials and Heat Treatment, 31, 10-14. 